\title{
The potential predictive risk of not measuring a potential predictor of risk
}

Verdi J. DiSesa, MD, MBA

See related article on pages 1606-12.

What is the ideal management of mitral regurgitation secondary to ischemic heart disease in patients undergoing coronary artery bypass grafting (CABG) surgery? What are the factors that might predict the need for a procedure on the valve itself as part of an operation to revascularize the myocardium? The article in this issue of the Journal by Sun and coauthors ${ }^{1}$ reports a retrospective analysis seeking to identify independent predictors of improvement in moderate mitral insufficiency in 109 patients undergoing isolated off-pump CABG after posterior-inferior myocardial infarction. None of the patients underwent mitral valve repair procedures, and slightly more than half of them had improvement in mitral valve function. According to multivariate regression analysis, 3 factors (higher left ventricular ejection fraction, greater posterior-inferior left ventricular volume ratio, and operation earlier after myocardial infarction) emerged as independent predictors of reduction in mitral insufficiency. The viability of the myocardium in the infarct zone was not assessed before or after the operation. Sun and coauthors ${ }^{1}$ suggest that the identified factors are indices of ventricular remodeling, which should be used to help guide management of patients with ischemic mitral valve insufficiency and which include an enhanced benefit from earlier revascularization surgery.

As Sun and coauthors ${ }^{1}$ correctly note, the question of the optimal management of the mitral valve in patients with postinfarction mitral insufficiency remains open. The data presented in this article begin to provide a scientific basis for predicting who might benefit from CABG alone (and therefore which patients with a posterior-inferior infarct would not need a reparative procedure on the mitral valve in addition to coronary revascularization). A potentially important omission in this analysis is the failure to record and report data that would allow an assessment of myocardial viability in the

\footnotetext{
From the Department of Surgery, Temple University School of Medicine, Philadelphia, Pa.

Disclosures: Author has nothing to disclose with regard to commercial support.

Received for publication April 5, 2015; accepted for publication April 6, 2015; available ahead of print May 1, 2015.

Address for reprints: Verdi J. DiSesa, MD, MBA, Department of Surgery, Temple University School of Medicine, 3500 N Broad St, MERB 11, Philadelphia, PA 19140 (E-mail: verdi.disesa@gmail.com).

J Thorac Cardiovasc Surg 2015;149:1613

$0022-5223 / \$ 36.00$

Copyright (c) 2015 by The American Association for Thoracic Surgery

http://dx.doi.org/10.1016/j.jtcvs.2015.04.018
}

posterior-inferior left ventricular infarct zone. Dysfunction and anatomic alteration of the ischemic or infarcted myocardium in this location often affects mitral valve geometry and function. Bypass surgery likely improves ventricular geometry and function in ischemic but viable myocardium. Therefore an alternative explanation of the findings of Sun

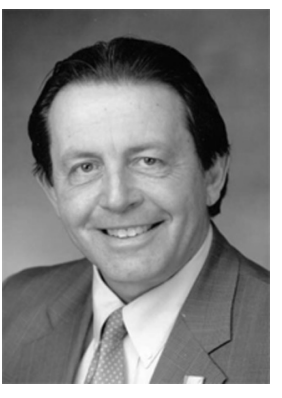
and coauthors ${ }^{1}$ could be that there was more viable heart muscle in the infarct area, the function of which improved postoperatively, in the patients who had better valve function after CABG alone. This inference gains support from the observation that operation earlier after myocardial infarction was a predictor of improvement in mitral regurgitation. In other words, the sooner ischemic but viable muscle is revascularized, the more complete is the recovery of both regional ventricular and mitral valve function. The absence of consideration of myocardial viability in this study potentially reduces the predictive power of the analysis by Sun and coauthors because it fails to consider a potentially important risk determinant of outcome.

Although Sun and coauthors ${ }^{1}$ did report which of the 3 main coronary vessel distributions were revascularized (there were no differences between patients with and without improvement), more detail about the quality of the vessels to the posterior-inferior ventricle and whether the "infarct vessel" was bypassed might also be useful. Such information might contribute significantly to understanding the potential role of myocardial viability in postoperative improvement in mitral valve function. Finally, the question posed by Sun and co-authors' work seems appropriate for a prospective study of patients with this condition randomly assigned to undergo $\mathrm{CABG}$ alone or CABG combined with a mitral repair operation. Inclusion of a determination of myocardial viability into a study of this design might yield results with even better predictive power.

\section{Reference}

1. Sun X, Huang J, Shi M, Huang G, Pang L, Wang Y. Predictors of moderate ischemic mitral regurgitation improvement after off-pump coronary artery bypass. J Thorac Cardiovasc Surg. 2015;149:1606-12. 